\title{
ANNOUNCEMENTS
}

\author{
THE ROYAL COLLEGE OF PATHOLOGISTS \\ London \\ One-day symposium
SAFE FOOD AND THE CHALLENGE OF COOK CHILL CATERING \\ Tuesday, 16 May 1989 \\ at the \\ Royal College of Pathologists \\ 2 Carlton House Terrace \\ London SW1
}

This symposium is open to members of the College, to trainee pathologists and to workers in other disciplines with an interest in medical microbiology.

Further details and application forms may be obtained from:

\author{
Scientific Meetings Officer \\ Royal College of Pathologists \\ 2 Carlton House Terrace \\ London SW1Y 5AF
}

(Tel: 01-930-5861)

\section{PATHOLOGICAL SOCIETY FELLOWSHIPS}

The Pathological Society of Great Britain and Ireland is sponsoring a small number of Fellowships to members of the medical and scientific professions working in UK or Ireland in experimental and/or pathologically or microbiologically-related medical research to visit other institutions for periods up to 12 months to learn new investigative techniques. Preference will be given to those requiring additional funds to augment existing salary. Further details and application forms from Professor R. B. Goudie, Department of Pathology, Royal Infirmary, Glasgow G4 0SF.

\section{CURRENT MEDICAL LITERATURE-INFECTIOUS DISEASES}

Glaxo Laboratories Ltd are sponsoring a number of subscriptions to this journal which they wish to make available to readers of the Journal of Medical Microbiology. The publication is intended to provide its readers with a manageable source of information on current developments, advances and controversies selected from a comprehensive scanning of the international literature. It is published by Current Medical Literature Ltd in conjunction with the Royal Society of Medicine. If you are interested in this offer please contact Dr E Rawlinson, Current Medical Literature Ltd, 40-42 Osnaburgh Street, London NW1 3ND. 